\title{
Systemic and local immunological features of atopic dermatitis patients with ocular complications
}

\author{
Eiichi Uchio, Kanata Miyakawa, Zenro Ikezawa, Shigeaki Ohno
}

\begin{abstract}
Aims-Clinical factors and data from recent cases of atopic dermatitis (AD) (with or without ocular complications) and non-AD cases were examined to evaluate the mechanism of atopic ocular complications.

Methods-IgE-RAST for eight allergens including rice, egg, and mite and serum total IgE were measured in 216 patients with AD (70 ocular type, 146 non-ocular type) and 69 non-AD individuals. Tear histamine and leukotriene $B_{4}\left(\right.$ LTB $\left._{4}\right)$ levels were also measured.

Results-The serum levels of IgE were significantly increased in AD patients with ocular complications compared with those without ocular complications. The positive rates of IgE-RAST for rice and wheat were significantly higher in ocular type AD than in non-ocular type AD. In ocular type AD, serum IgE was significantly increased in patients with cataract compared with that in those without cataract. Tear histamine and $\mathrm{LTB}_{4}$ levels in $\mathrm{AD}$ patients with ocular complications showed significant elevations compared with those in patients with pure AD and controls.

Conclusions-These results suggest that ocular type AD belongs to the most severe end of the spectrum of $A D$, and that some food antigens may contribute to the pathogenesis of severe $\mathrm{AD}$ resulting in ocular complications.

(Br F Ophthalmol 1998;82:82-87)
\end{abstract}

Ophthalmology,

Yokohama City

University School of

Medicine, Yokohama,

Japan

E Uchio

S Ohno

Department of

Dermatology,

Yokohama City

University School of

Medicine, Yokohama,

Japan

K Miyakawa

Z Ikezawa

Correspondence to: Eiichi Uchio, MD Department of

Ophthalmology, Yokohama City University School of Medicine, 3-9 Fuku-ura, Kanazawa, Yokohama 236, Japan.

Accepted for publication 8 September 1997 have been well studied, since many paediatricians have long insisted that they are the three major allergens causing infantile $\mathrm{AD},{ }^{10-14}$ but cereal allergens such as rice and wheat have not received the same attention. Recently, the incidence of the severe type of $\mathrm{AD}$, which is not well controlled by local steroid treatment, has been noted to be increasing. ${ }^{8}$ Although several authors have reported the characteristics of ocular complications of $\mathrm{AD},{ }^{2-6}$ to our knowledge, the pathophysiological features of the ocular complications of AD have not been described. In this paper we compared the immunological features, systemic and local, of patients with $\mathrm{AD}$ of the ocular and non-ocular types and examined what kind of allergens may be related specifically to the development of atopic ocular complications.

\section{Materials and methods}

SUBJECTS AND DIAGNOSTIC CRITERIA FOR AD In all, 216 patients with typical lesions of $\mathrm{AD}$ were included in this study. Definite AD was diagnosed, according to criteria proposed by Hanifin and Rajka, ${ }^{15}$ by the presence of four items: (1) itching, (2) chronic course of more than 1 year, (3) atopic history, and (4) typical lesions of $\mathrm{AD}$. The historical data, age at onset, clinical course of the dermatitis, personal and family history of atopy, use of steroids, complications, and response to treatment were recorded. All the patients with a definite clinical diagnosis of AD at the Department of Dermatology, Yokohama City University Hospital were referred to the Department of Ophthalmology, Yokohama City University Hospital and examined for signs of ocular disease even if they complained of no ocular symptoms. Ocular complications were present in $70 \mathrm{AD}$ patients (group 1, AD + eye group; 25 women and 45 men; mean age, 24.8 (SD 7.8) years; range, 13-58). The non-ocular $\mathrm{AD}$ group was divided into three subgroups according to other non-ocular complications as follows: patients without any complications (group 2, pure $\mathrm{AD}$ group; 38 women and 47 men; mean age, 25.6 (SD 8.1) years; range 11-54), patients with bronchial asthma (group 3, AD + BA group; 17 women and 15 men; mean age, 13.1 (SD 9.7) years; range 5-51), and patients with allergic rhinitis (group 4, AD + AR group; 15 women and 14 men; mean age, 25.4 (SD 11.9) years; range 13-59). Serum samples from 69 healthy individuals were also examined (group 5, controls; mean age, 29.4 (SD 11.7) years; range 9-66).

GRADING OF CLINICAL DERMATOLOGICAL SEVERITY

The clinical severity of the AD lesions was graded as (I) mild, (II) moderate, or (III) 
severe, according to the distribution of the lesions, response to therapy, frequency of relapse, and the clinical course, as follows ${ }^{8}$; (I) mild - the lesions were relatively limited or disparately scattered, readily responsive to therapy, rarely relapsing, and the course was short; (II) moderate-the lesions were widespread or occasionally limited, relatively responsive to therapy, but often relapsed with a chronic course; (III) severe-the lesions were widespread or occasionally limited, refractory to therapy, and had a protracted course.

MEASUREMENT OF SPECIFIC IgE ANTIBODY AND SERUM IgE LEVEL

Serum levels of IgE antibodies specific to inhalant and food antigens were determined with the CAP system (Pharmacia CAP System RAST FEIA, Pharmacia, Uppsala, Sweden). Firstly, $50 \mu \mathrm{l}$ of samples including standards was absorbed with Immuno CAP, and incubated for 30 minutes. Just before the end of the incubation, $50 \mathrm{ml}$ of enzyme linked anti-IgE antibody was added to each well. After washing, the samples were incubated for 150 minutes. After further washing, $50 \mu \mathrm{l}$ of developing solution was added. After incubation for 10 minutes, the reaction was halted by adding stop solution and the fluorescence was measured with a Fluoro Count 96 (Pharmacia, Uppsala, Sweden). The concentration of the patient samples was read from a standard curve. The results were expressed in $\mathrm{kU}_{\mathrm{A}} / 1$ and classified according to the RAST scoring system $\left(0:<0.35 \mathrm{kU}_{\mathrm{A}} / 1,1: 0.35 \sim 0.69,2: 0.7 \sim\right.$ 3.4, 3: $\left.3.5 \sim 17.4,4: \geqslant 117.5 \mathrm{kU}_{\mathrm{A}} / 1\right)$. A result exceeding $0.69 \mathrm{kU}_{\mathrm{A}} / 1$ (score $\geqslant 12$ ) was considered positive. Serum total IgE level was also measured.

TEAR HISTAMINE AND LEUKOTRIENE B4 LEVELS Tear samples were collected from 42 patients who were divided into three groups: group $\mathrm{A}$ included 14 patients with $\mathrm{AD}$ who had ocular complications; group B included 16 patients with $\mathrm{AD}$ who had no clinical signs other than skin lesions; group $\mathrm{C}$ included 12 healthy controls. Cases in groups $\mathrm{A}, \mathrm{B}$, and $\mathrm{C}$ were selected randomly from groups 1, 2, and 5, respectively. The mean age in each group showed no significant difference. Two separate filter paper strips were superimposed and then placed in the inferior fornix. In this manner it was possible to demonstrate that the entire spectrum of mediators being assayed was generated in the same sample of tear fluid. Each filter paper was frozen at $-80^{\circ} \mathrm{C}$ until assay.

One of the two preweighed filter paper strips was placed immediately into a preweighed tube containing $300 \mu \mathrm{l}$ of isotonic saline for the determination of histamine.
When samples were thawed, fluids for the determination of histamine were divided into aliquots and assayed at appropriate dilutions. Histamine was measured in $50 \mu \mathrm{l}$ aliquots of fluid by a radioenzymatic assay with a detection limit of $50 \mathrm{pg} / \mathrm{ml}$. This assay uses partially purified histamine $\mathrm{N}$-methyl transferase from rat kidney and S-adenosyl-C- $\left[{ }^{3} \mathrm{H}\right]-$ methyl-methionine (Amersham Japan, Tokyo, Japan) to convert histamine to $\left[{ }^{3} \mathrm{H}\right]-$ methylhistamine, which is then isolated from other radiolabelled materials and quantified by liquid scintillation counting. A standard curve ranging from $50 \mathrm{pg} / \mathrm{ml}$ to $10000 \mathrm{pg} / \mathrm{ml}$ was used in each experiment.

The remaining filter paper strip for the measurement of leukotriene $\mathrm{B}_{4}\left(\mathrm{LTB}_{4}\right)$ was put into a separate vial containing $0.5 \mathrm{ml} \mathrm{Krebs-}$ Ringer bicarbonate buffer, $\mathrm{pH}$ 7.4, and was centrifuged for 15 minutes at room temperature, following which samples were obtained from the incubation medium for $\mathrm{LTB}_{4}$ determination. $\mathrm{LTB}_{4}$ was determined by radioimmunoassay, using specific antibodies. For $\mathrm{LTB}_{4}$, we used antibodies from Amersham Japan, with cross reactivity of $3.5 \%$ with 5,12 dihydroxyeicosatetraenoic acid and less than $1 \%$ with other arachidonic acid derivatives.

\section{STATISTICS}

The significance of differences in clinical dermatological severity of $\mathrm{AD}$ and percentage positivity of IgE RAST between patient groups was determined by the $\chi^{2}$ test. The MannWhitney test was used to identify significant differences in serum total IgE level and tear histamine and $\mathrm{LTB}_{4}$ levels between groups.

\section{Results}

OCULAR COMPLICATIONS

Of the 216 patients, 70 (32.4\%) had significant ocular disease. Conjunctival, corneal, lens, and retinal disorders were observed in $59(84.3 \%)$, $26(37.1 \%), 29(41.4 \%)$, and $16(22.9 \%)$ patients, respectively. Of the 29 patients with cataract, five had received significant steroid therapy. In this study, atypical lens opacities in patients over 40 years old were excluded, since senile cataract might be involved in those cases. Four patients suffered from retinal detachment and underwent successful surgery.

\section{COMPARISON OF DERMATOLOGICAL SEVERITY} BETWEEN AD PATIENT GROUPS

Table 1 compares the dermatological severity between two different patient groups of $\mathrm{AD}$; firstly, between patients with ocular complications (group 1) and those with no ocular complications (groups 2-4); secondly, among those with ocular complications, between patients

Table 1 Comparison of dermatological severity between AD patient groups

\begin{tabular}{|c|c|c|c|c|c|}
\hline & \multirow{2}{*}{$\begin{array}{l}\text { No of } \\
\text { patients }\end{array}$} & \multicolumn{3}{|c|}{ Dermatological severity } & \multirow[b]{2}{*}{$p$ Value ( $\chi^{2}$ test $)$} \\
\hline & & Mild & Moderate & Severe & \\
\hline AD with ocular complications (group 1) & 70 & 6 & 30 & 34 & $<0.025 v$ group $2-4$ \\
\hline Patients with cataract (group 1A) & 29 & 0 & 7 & 22 & $<0.001 v$ group $1 \mathrm{~B}$ \\
\hline Patients without cataract (group 1B) & 41 & 6 & 23 & 12 & \\
\hline AD without ocular complications (groups $2-4$ ) & 146 & 41 & 59 & 46 & \\
\hline
\end{tabular}




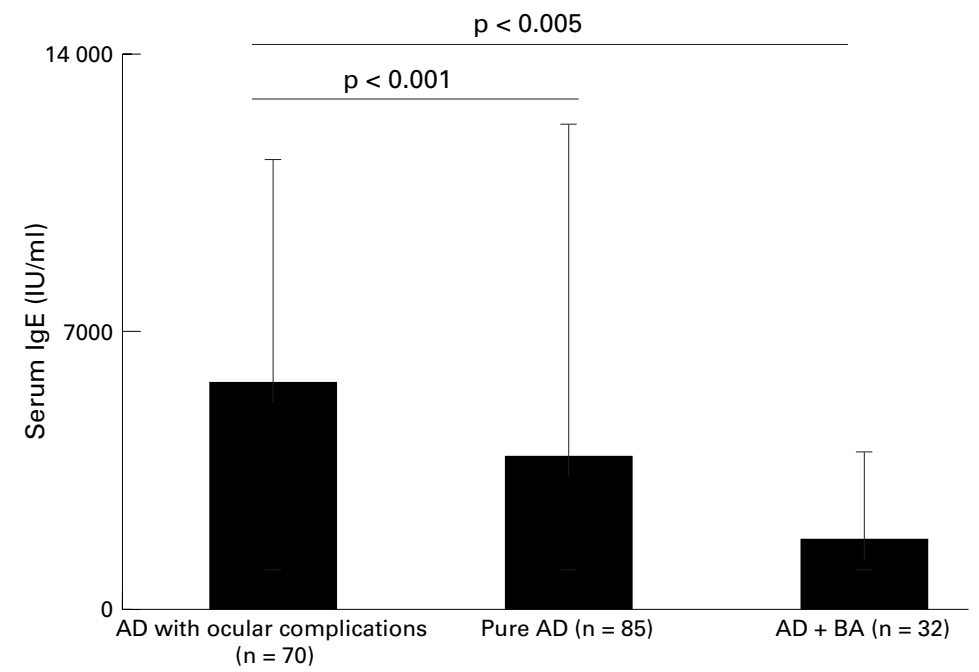

Figure 1 Serum IgE levels in AD patients with ocular complications (group 1, AD + eye group), $A D$ patients without any complications (group 2 , pure $A D$ group), and $A D$ patients with bronchial asthma (group 3, $A D+B A$ group). Each bar represents the mean and standard deviation of serum IgE levels.

with cataract (group 1A) and those with no sign of cataract (group 1B). Severe cases of AD comprised $48.6 \%(34 / 70)$ of group 1 and $31.5 \%(46 / 146)$ of groups $2-4$. This difference was significant $(\mathrm{p}<0.025)$. In addition, dermatologically severe cases were more common in patients with cataract $(22 / 29(75.9 \%))$ than in non-cataract patients $(12 / 41(29.3 \%))$ ( $\mathrm{p}$ $<0.001)$.

RELATION BETWEEN SYSTEMIC COMPLICATIONS AND SERUM IgE

We compared serum IgE levels in the three patient groups, AD with ocular complications (group 1, AD + eye group), $\mathrm{AD}$ without any complications (group 2, pure $\mathrm{AD}$ group) and $\mathrm{AD}$ with bronchial asthma (group $3, \mathrm{AD}+\mathrm{BA}$ group). As shown in Figure 1, the serum levels of IgE were significantly increased in the AD + eye group compared with the pure $\mathrm{AD}$ group or $\mathrm{AD}+\mathrm{BA}$ group $(\mathrm{p}<0.001,0.005$, respectively). The difference in levels of serum $\mathrm{IgE}$ between pure $\mathrm{AD}$ and $\mathrm{AD}+\mathrm{BA}$ groups was not significant.

COMPARISON OF RAST REACTIONS TO ALLERGENS BETWEEN PATIENT GROUPS

The RAST scores for groups 1-5 are presented in Table 2. IgE-RAST of almost all allergens in
non-AD individuals (group 5) showed a significantly lower positive rate than that in each type of $\mathrm{AD}$ patients (groups 1-4). The RAST scores for wheat were positive in 37 of 70 patients $(52.9 \%)$ with $\mathrm{AD}$ having ocular complications, whereas scores were positive in only 28 of 85 patients $(32.9 \%)$ with pure AD (group 2) and four of 25 patients $(16.0 \%)$ with $\mathrm{AD}+\mathrm{AR}$ (group 4). These differences were significant ( $\mathrm{p}<0.05,0.005$, respectively). The RAST scores for rice were also significantly elevated in patients with $\mathrm{AD}$ and ocular complications (group 1) (49/70 (70.0\%)) compared with those in patients with pure AD (group 2) (28/85 (32.9\%)) and patients with $\mathrm{AD}+\mathrm{AR}$ (group 4) (5/25 (20.0\%)) (p $<0.001)$.

COMPARISON OF SERUM IgE AMONG AD PATIENT GROUPS WITH OCULAR COMPLICATIONS

$\mathrm{AD}$ patients with ocular complications were divided into four subgroups: those with cataract (CAT group), those with retinal disorders (RET group), those with both cataract and retinal complications (CAT + RET group), and those with only conjunctival and/or corneal disorders (Others group). The serum levels of $\operatorname{IgE}$ were significantly increased in the RET + CAT group and the CAT group compared with the Others group $(\mathrm{p}<0.05$, 0.01 , respectively) (Fig 2).

COMPARISON OF TEAR HISTAMINE AND LTB 4 LEVELS AMONG PATIENT GROUPS

While tear histamine levels were not significantly elevated in pure AD patients (group B) (83.1(SD 101) pg/ml; histamine levels of eight patients were below the detection limit) when compared with levels in controls (group C) (47.9 (64.4) $\mathrm{pg} / \mathrm{ml}$; histamine levels of six patients were below the detection limit), significant elevation $(\mathrm{p}<0.001)$ was observed in tear histamine levels in patients with $\mathrm{AD}$ with ocular complications (group A) (354 (148) $\mathrm{pg} / \mathrm{ml}$ ) compared with those in both patients with pure $\mathrm{AD}$ and controls (Fig 3). The tears from symptomatic ocular $\mathrm{AD}$ patients (group A) showed elevated levels of $\mathrm{LTB}_{4}(1000$ (324) $\mathrm{pg} / \mathrm{ml})$, compared with those from patients with $\mathrm{AD}$ who had no ocular complications (group B) $(144(121) \mathrm{pg} / \mathrm{ml})$ and the control group (group C) (109 (63.5) $\mathrm{pg} / \mathrm{ml}$ ). These results were found to be signifi-

Table 2 Comparison of RAST reactions to inhalant and food allergens between patient groups

\begin{tabular}{|c|c|c|c|c|c|c|c|c|c|}
\hline & \multirow{3}{*}{$\begin{array}{l}\text { No of } \\
\text { patients }\end{array}$} & \multicolumn{8}{|c|}{$\%$ of RAST positive patients } \\
\hline & & \multicolumn{8}{|c|}{ Antigen } \\
\hline & & $D F$ & Egg white & Milk & Mugwort & Soybean & Wheat & Rice & Candida \\
\hline $\mathrm{AD}+$ eye (group 1$)$ & 0 & $77.1^{\star}$ & 22.99 & 4.3 & $40.0^{\star}$ & $35.7^{\star}$ & $52.9^{\star}$ & $70.0^{\star}$ & $42.9^{\star}$ \\
\hline Pure AD (group 2) & 85 & $74.1^{\star}$ & $16.5 \$$ & $17.6 \dagger$ & $42.4^{\star}$ & $28.2^{\star}$ & $32.9^{\star}$ & $32.9^{\star}$ & $50.6^{\star}$ \\
\hline $\mathrm{AD}+\mathrm{BA}($ group 3$)$ & 32 & $93.8^{\star}$ & $37.5^{\star}$ & 25.0 & $31.3+$ & $21.9 \rrbracket$ & $37.5^{\star}$ & $37.5^{\star}$ & $46.9^{\star}$ \\
\hline $\mathrm{AD}+\mathrm{AR}$ (group 4) & 25 & $76.0^{\star}$ & 0 & 0 & 20 & $16.0 \S$ & $16.0 \Omega$ & $20.0 \$$ & $52.0^{\star}$ \\
\hline Controls (group 5) & 69 & 34.8 & 4.3 & 2.9 & 8.7 & 1.4 & 1.4 & $2.9^{\circ}$ & 10.1 \\
\hline
\end{tabular}

$\mathrm{DF}=$ Dermatophagoides farinae, mite antigen; Candida $=$ Candida albicans.

Significance between patient groups and controls is indicated by symbols: ${ }^{\star} \mathrm{p}<0.001, \uparrow \mathrm{p}<0.005,+\mathrm{p}<0.01, \$ \mathrm{p}<0.05$, Significance among patient groups is shown below.

DF: $\mathrm{p}<0.05$ between group 2 and group 3.

Egg white: $\mathrm{p}<0.005$ between group 3 and group $4 ; \mathrm{p}<0.05$ between group 1 and group 4 , and group 2 and group 3.

Milk: $\mathrm{p}<0.05$ between group 1 and group 2 , and group 3 and group $4 ; \mathrm{p}<0.01$ between group 1 and group 3 .

Wheat: $\mathrm{p}<0.05$ between group 1 and group $2 ; \mathrm{p}<0.005$ between group 1 and group 4 .

Rice: $\mathrm{p}<0.001$ between group 1 and group 2 , and group 1 and group $4 ; \mathrm{p}<0.005$ between group 1 and group 3 . 


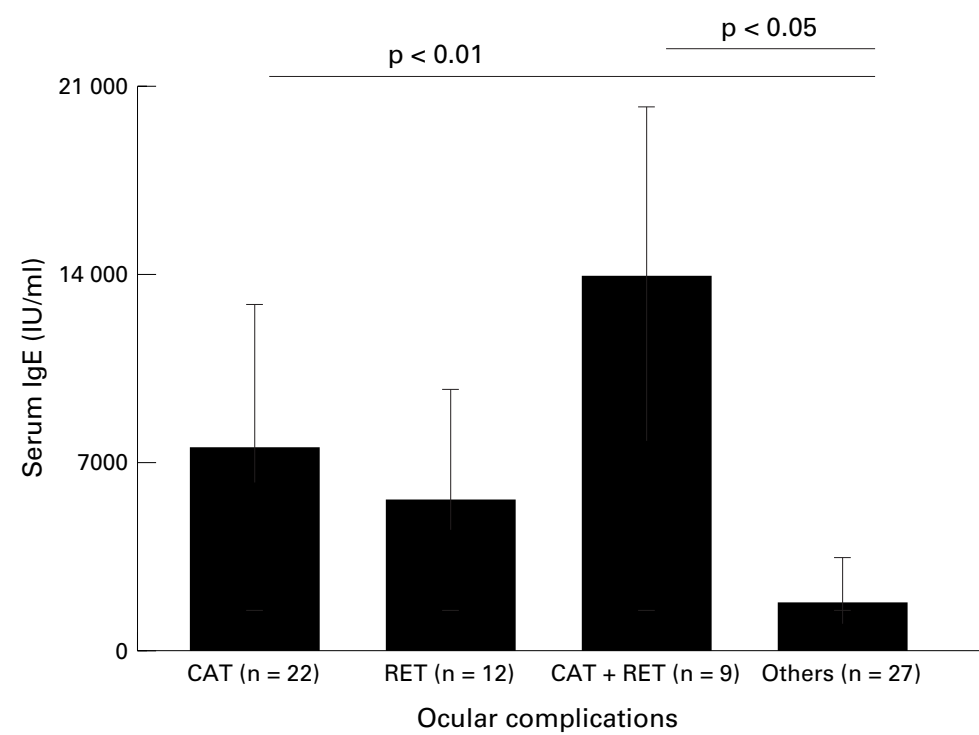

Figure 2 Serum IgE levels in AD patient groups with ocular complications. $C A T=$ patients with cataract; $R E T=$ patients with retinal disorders; $C A T+R E T=$ patients with both cataract and retinal complications; Others = patients with only conjunctival and/or corneal disorders. Each bar represents the mean and standard deviation of serum IgE levels.

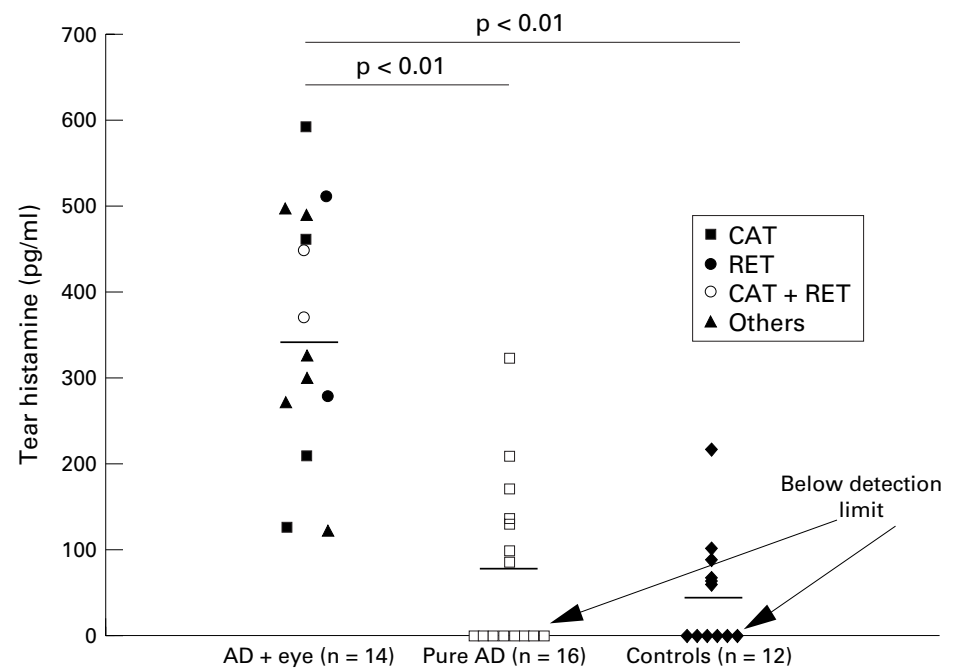

Figure 3 Tear histamine levels in AD patients with ocular complications (group $A$ ), $A D$ patients without any complications (group B), and healthy controls (group $C$ ). Group $A$ is divided into four subgroups, CAT, RET, CAT + RET, and Others. Abbreviations are as for Figure 2. Each bar represents the mean of tear histamine levels.

cant $(\mathrm{p}<0.001)$ (Fig 4). No significant difference was found in the increased levels of both tear chemical mediators among the subgroups of patients with significant ocular lesions, such as cataract, retinal disorders, cataract + retinal disorders, and others.

\section{Discussion}

Although there are a limited number of studies on the frequency of ocular complications in $\mathrm{AD}$ populations, they have been reported in $42.5 \%$ of $\mathrm{AD}$ patients. ${ }^{6}$ In our study, 70 out of 216 AD patients $(32.4 \%)$ showed ocular complications. Cataract has been found in $3-25 \%^{26}{ }^{16}$ of patients with AD. Most of the cataracts in our study were primary anterior or posterior subcapsular, and there was no significant use of systemic steroids in both types, suggesting that there was no significant relation between the systemic use of steroids and either the development or the type of cataract.

In the present study, we showed a significant difference in serum IgE levels between $\mathrm{AD}$ patients with and without ocular complications (Fig 1). Serum IgE levels were higher in the pure $\mathrm{AD}$ group compared with the $\mathrm{AD}+\mathrm{BA}$ group. This result is considered to be due to the younger mean age in the $\mathrm{AD}+\mathrm{BA}$ group compared with the pure AD group, since serum IgE level is considered to reflect the length of atopic history. ${ }^{8}$

Several authors have reported on the incidence of the positive RAST reactions in patients with AD. Positive RAST reactions to Dermatophagoides farinae (DF; mite antigen) have been reported in $73 \%$ of Japanese patients. ${ }^{17}$ Although DF-RAST positivity in our present study was highest in the AD + BA group (93.8\%), controls also showed a relatively high positive rate $(34.8 \%)$, probably due to the humid and hot climate and housing conditions with the use of floor mats in Japan. The probable involvement of rice allergy in many severe cases of AD is suggested from a statistical analysis of the correlation between rice-RAST scores and dermatological severity in $\mathrm{AD}$ patients. ${ }^{8}$ Elimination of rice from the diet in severe cases has been reported to result in varying degrees of clinical improvement. ${ }^{18}$ Present results indicate that although all patients with $\mathrm{AD}$ are equally exposed to food allergens, only a limited number of patients develop type I allergy to foods. This would suggest that patients with $\mathrm{AD}$ vary in their capacity to develop type I food allergy. Furthermore, there is still a possibility that inhalant allergens also play an important role in the pathogenesis of various atopic symptoms. As shown in Table 2, among food antigens, the positive RAST rates of rice and wheat were significantly higher in AD patients with ocular complications than in other AD patients. The positive RAST rates to rice and wheat antigens are reported to be $38-49.7 \%$ and $21-32 \%$, respectively, in Japan. ${ }^{817}$ In contrast, in the USA a positive reaction against rice and wheat is obtained in $0-7 \%$ and $13-19 \%$, respectively. ${ }^{11}{ }^{19}$ The reason for these different RAST reactions to cereal antigens between Japan and USA has not yet been clearly explained. Statistical analysis also revealed a close correlation between each RAST score for rice and wheat in AD patients with ocular complications $(r=0.925, \mathrm{p}<$ 0.001 , data not shown). This correlation among RAST scores for cereal antigens suggests that these antigens share some cross reactive epitopes for specific $\operatorname{IgE}$ antibodies and this is supported by absorption experiments. ${ }^{8}$

We compared serum IgE levels in AD patients with ocular complications to clarify whether immunological reactions differ in different types of ocular complications. Our results suggested that type I allergy plays an important role in the development of cataract (Fig 2). Therefore, it seems reasonable to consider that ocular diseases in $\mathrm{AD}$ patients, such as cataract and retinal detachment, are due to persistent ocular trauma 


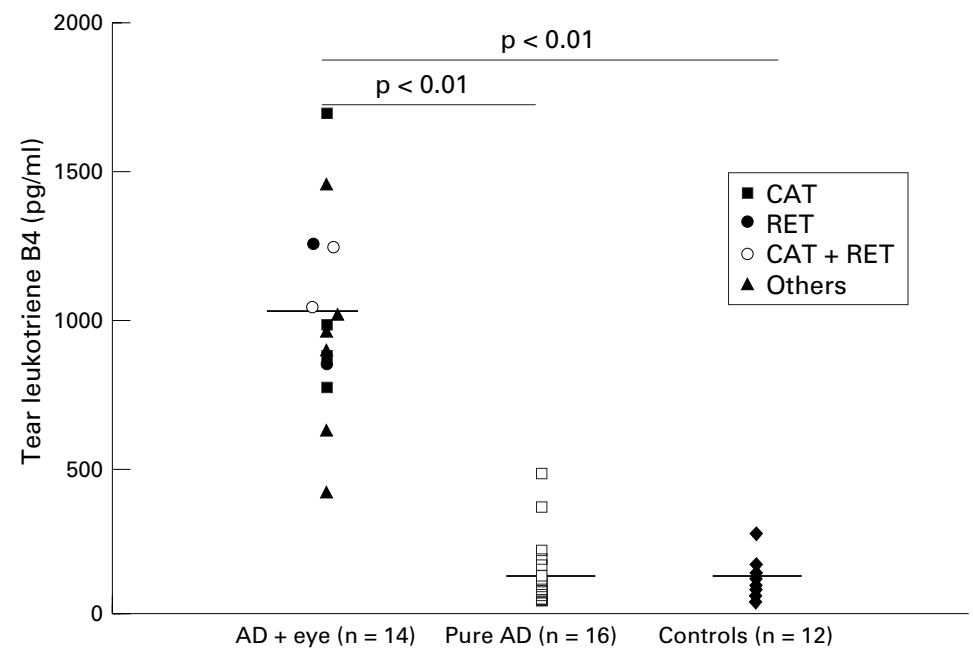

Figure 4 Tear leukotriene $B_{4}\left(L T B_{4}\right)$ levels in AD patients with ocular complications (group $A$ ), AD patients without any complications (group B), and healthy controls (group C). Group $A$ is divided into four subgroups, CAT, RET, CAT + RET, and Others.

Abbreviations are as for Figure 2. Each bar represents the mean of tear $\mathrm{LTB}_{4}$ levels.

which is common in patients with the severe type of AD. ${ }^{16}$ However, it cannot be ruled out from the present results that some kind of autoimmune reaction, especially to extraocular crystallins, exists in AD patients. ${ }^{20}{ }^{21}$ Our data confirm the observation that type I allergy to foods plays an important role in the development of severe $\mathrm{AD}$ and its ocular complications. However, there remains controversy as to whether the severity of $\mathrm{AD}$ can be explained only by the severity of type I allergy, as reflected by serum IgE levels and IgE-RAST. Supported by the knowledge that Ag specific immunoglobulin production is regulated by $\mathrm{CD}^{+}{ }^{+} \mathrm{T}$ cells with the same specificity, ${ }^{22}$ and the finding that murine $\operatorname{IgE}$ synthesis in vivo is also regulated by interleukin 4 (IL-4) and interferon gamma (IFN- $\gamma),{ }^{23}{ }^{24}$ it is possible that type IV allergy may also play a critical pathogenesis of $\mathrm{AD}^{25}$

Tear levels of histamine and $\mathrm{LTB}_{4}$ were examined to evaluate whether ocular complications in $\mathrm{AD}$ patients reflect the systemic severity of atopy or indicate a local immune response that is characteristic of $\mathrm{AD}$ patients with ocular complications. The present study showed significantly higher levels of histamine and $\mathrm{LTB}_{4}$ in the tears of $\mathrm{AD}$ patients with ocular complications. Histamine acts as a primary chemical mediator, stimulating the secondary production and release of prostaglandin $\mathrm{I}_{2}$ during allergic conjunctival reaction. ${ }^{26} \mathrm{LTB}_{4}$ is a potent chemotactic factor for polymorphonuclear leucocytes and eosinophils and $\mathrm{LTB}_{4}$ is generated predominantly by mast cells and macrophages. ${ }^{27}$ Tear levels of histamine are reported to be increased in a vernal conjunctivitis model in guinea pigs. ${ }^{26}$ Levels of $\mathrm{LTB}_{4}$ in tears of humans with vernal conjunctivitis are also elevated. ${ }^{28}$ In contrast, both histamine and $\mathrm{LTB}_{4}$ levels in patients with allergic conjunctivitis show no significant increase. ${ }^{29}$ To our knowledge, the levels of tear histamine and $\mathrm{LTB}_{4}$ in patients with $\mathrm{AD}$ who have ocular complications have not been described. In our study, tear histamine and $\mathrm{LTB}_{4}$ levels in $\mathrm{AD}$ patients with ocular complications showed sig- nificant elevations compared with those in patients with pure $\mathrm{AD}$ and controls. These findings indicate that high levels of histamine and $\mathrm{LTB}_{4}$ in the eyes of $\mathrm{AD}$ patients contribute to the development of ocular complications. Therefore, it is suggested that the immunological reaction in ocular type $\mathrm{AD}$ patients is significantly activated not only systemically but also locally.

In conclusion, although further studies are needed to elucidate the precise immunological mechanism of severe AD with ocular complications, our data indicate a clear correlation between the presence of ocular complications and a high serum IgE level or positive rate of RAST scores to cereal antigens. Moreover, the local immune response is significantly activated in $\mathrm{AD}$ patients with ocular complications compared with those without ocular complications.

We wish to thank Pharmacia Co Ltd for providing CAP System RAST FEIA.

1 Hanifin JM. Atopic dermatitis. F Allergy Clin Immunol 1984;73:211-26.

2 Brunsting LA, Reed WB, Bair HL. Occurrence of cataract and keratoconus with atopic dermatitis. Arch Dermatol 1955;72:237-41. 3 Hogan MJ. Atopic keratoconjunctivitis. Am f Ophthalmol

4 Easty D, Entwistle C, Funk A, Witcher J. Herpes simplex keratitis and keratoconus in the atopic patient: a clinical and immunological study. Trans Ophthalmol Soc UK 1975;

5 Ingram RM. Retinal detachment associated with atopic dermatitis and cataract. Br F Ophthalmol 1965;49:96-7.

6 Garrity JA, Liseseang TJ. Ocular complications of atopic dermatitis. Can 7 Ophthalmol 1984;19:21-4.

7 Okudaira $\mathrm{H}$, Hongo O, Ogita T, et al. Serum IgG and IgE antibody levels in patients with bronchial asthma, atopic dermatitis, eosinophilic granulomas of the soft tissue (Kimura's disease) and other diseases. Ann Allergy 1983;50:51-4.

8 Ikezawa Z, Miyakawa K, Komatsu H, et al. A probable involvement of rice allergy in severe type of atopic dermatitis in Japan. Acta Derm Venereol Suppl (Stockh) 1992;176: 103-7.

9 Uehara M, Kimura C, Uenishi T. Type I allergy to foods in atopic dermatitis. Acta Derm Venereol Suppl (Stockh) 1992; 176:38-40.

10 de Marino M, Donzelli GP, Gallil L, et al. Food allergy in preterm infants fed human milk. Biol Neonat 1989;56:301-5.

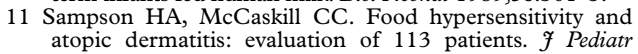
atopic dermatitis:

12 Gustafsson D, Lowhagen T, Andersson K. Risk of developing atopic disease after early feeding with cow's milk based formula. Arch Dis Child 1992;67:1008-10

13 Casimir GJA, Duchateau J, Gossart B, et al. Atopic dermatitis: role of food and house dust mite allergens. Pediatrics 1993;92:252-6.

14 Sampson HA, Albergo R. Comparison of results of skin tests, RAST, and double-blind, placebo-controlled food challenges in children with atopic dermatitis. F Allergy Clin Immunol 1984;74:26-33.

15 Hanifin JH, Rajka G. Diagnostic features of atopic dermatitis. Acta Derm Venereol Suppl (Stockh) 1980;92:44-7.

16 Amemiya T, Matsuda H, Uehara H. Ocular findings in atopic dermatitis with special reference to the clinical features of atopic cataract. Ophthalmologica 1980;180:129-31.

17 Miyakawa K. Analysis of clinical factors and IgE-RAST of Dermatophagoides farinae and rice in atopic dermatitis by Dermatophagoides farinae and rice in atopic dermatitis by
multiple factor analysis of quantification theory type II. $\mathscr{f p n}$ multiple factor analysis of quan

18 Komatsu H, Suga C, Miyakawa K, et al. The clinical symptoms, RAST titers for rice and wheat, serum IgE values and eosinophil number in atopic dermatitis patients fed an elimination diet of rice. Fpn F Allergy 1990;39:402-9.

19 Sampson HA. Role of immediate food hypersensitivity in the pathogenesis of atopic dermatitis. $\mathcal{F}$ Allergy Clin Immunol 1983;71:473-80.

20 Patel M, Shine B, Murray PI. Antilens antibodies in cataract and inflammatory eye disease:an evaluation of a new technique. Int Ophthalmol 1990;14:97-100.

21 Sandberg HO, Closs O. The alpha and gamma crystallin content in aqueous humor of eyes with clear lenses and with cataracts. Exp Eye Res 1979;28:601-10.

22 Schreier MH, Tees R, Nordin AA, et al. Functional aspects of helper T cell clones. Immunobiology 1982;161:107-38.

23 Finkelman FD, Katona IM, Urban JF, et al. Suppression of in vivo polyclonal IgE responses by monoclonal antibody to 
the lymphokine B-cell stimulatory factor 1. Proc Natl Acad Sci USA 1986;83:9675-8.

24 Finkelman FD, Katona IM, Mosmann TR, Coffman RL. IFN-g 4 regulates the isotypes of Ig secreted during in vivo humoral immune responses. F Immunol 1988;140:1022-7. 25 Wierenga EA, Snoek M, de Groot C, et al. Evidence for compartmentalization of functional subsets of $\mathrm{CD}^{+} \mathrm{T}$ lymphocytes in atopic patients. F Immunol 1990;144:4651-6.

26 Helleboid L, Khatami M, Wei Z-G, Rockey JH. Histamine and prostacyclin. Invest Ophthalmol Vis Sci 1991;32:2281-9.
27 Goetzl EJ. Inflammation and hypersensitivity. Int Ophthalmol Clin 1985;25:25-34.

28 Nathan H, Naveh N, Meyer E. Levels of prostaglandin $E_{2}$ and leukotriene $\mathrm{B}_{4}$ in tears of vernal conjunctivitis patients during a therapeutic trial with indomethacin. Doc Ophthalmol 1994;85:247-54

29 Bonini S, Bonini S, Berruto A, et al. Conjunctival provocation test as a model for the study of allergy and inflammation in humans. Int Arch Allergy Appl Immunol 1989;88: $144-8$ 